\title{
Exogenous peripheral blood mononuclear cells affect the healing process of deep-degree burns
}

\author{
GUANYING YU ${ }^{1,2^{*}}$, YAONAN $\mathrm{LI}^{3^{*}}, \mathrm{LAN} \mathrm{YE}^{4}$, XINGLEI WANG ${ }^{3}$, \\ JIXUN ZHANG ${ }^{1}$, ZHENGXUE DONG $^{5}$ and DUYIN JIANG ${ }^{1,3}$

\begin{abstract}
${ }^{1}$ Department of Burns and Plastic Surgery, The Second Hospital of Shandong University, Jinan, Shandong 250033; ${ }^{2}$ Department of Gastrointestinal Surgery, Jinan Central Hospital, Jinan, Shandong 250013; ${ }^{3}$ Department of Emergency;

${ }^{4}$ Cancer Center, The Second Hospital of Shandong University, Jinan, Shandong 250033; ${ }^{5}$ Department of Burns and

Plastic Surgery, The Chinese People's Liberation Army 148 Hospital, Zibo, Shandong 255300, P.R. China
\end{abstract}

Received May 15, 2016; Accepted July 20, 2017

DOI: $10.3892 / \mathrm{mmr} .2017 .7672$

\begin{abstract}
The regenerative repair of deep-degree (second degree) burned skin remains a notable challenge in the treatment of burn injury, despite improvements being made with regards to treatment modality and the emergence of novel therapies. Fetal skin constitutes an attractive target for investigating scarless healing of burned skin. To investigate the inflammatory response during scarless healing of burned fetal skin, the present study developed a nude mouse model, which was implanted with normal human fetal skin and burned fetal skin. Subsequently, human peripheral blood mononuclear cells (PBMCs) were used to treat the nude mouse model carrying the burned fetal skin. The expression levels of matrix metalloproteinase (MMP)-9 and tissue inhibitor of metalloproteinases (TIMP)-1 were investigated during this process. In the present study, fetal skin was subcutaneously implanted into the nude mice to establish the murine model. Hematoxylin and eosin staining was used to detect alterations in the skin during the development of fetal skin and during the healing process of deep-degree burned fetal skin. The expression levels of MMP-9 and TIMP-1 were determined using immunochemical staining, and their staining intensity was evaluated by mean optical density. The results demonstrated that fetal skin subcutaneously implanted into the dorsal skin flap of nude mice developed similarly to the normal growth process in the womb. In addition, the scarless healing process was clearly observed in the mice carrying the burned fetal
\end{abstract}

Correspondence to: Professor Duyin Jiang, Department of Burns and Plastic Surgery, The Second Hospital of Shandong University, 247 Beiyuan Street, Jinan, Shandong 250033, P.R. China

E-mail: jdybs2@vip.163.com

*Contributed equally

Key words: peripheral blood mononuclear cells, deep-degree burn, scarless healing, matrix metalloproteinase-9, tissue inhibitor of metalloproteinases-1 skin. A total of 2 weeks was required to complete scarless healing. Following treatment with PBMCs, the burned fetal skin generated inflammatory factors and enhanced the inflammatory response, which consequently resulted in a reduction in the speed of healing and in the formation of scars. Therefore, exogenous PBMCs may alter the lowered immune response environment, which is required for scarless healing, resulting in scar formation. In conclusion, the present study indicated that the involvement of inflammatory cells is important during the healing process of deep-degree burned skin, and MMP-9 and TIMP-1 may serve important roles in the process of scar formation.

\section{Introduction}

The regenerative repair of deep-degree (second degree) burned skin remains a notable challenge in the treatment of burn injuries, despite improvements being made to the treatment modality and the emergence of novel therapies (1). The healing outcome of burned skin depends on the depth and extent of the burn (2). Numerous patients suffer from extensive scar formation following deep-degree burns; therefore, these patients must undergo numerous surgeries over the years to alleviate their disability (3). When the degree of a burn injury is beyond the self-repairing and structural reconstructive capabilities of the skin, a local excessive inflammatory immune response is initiated, which is characterized by a large increase in inflammatory cell infiltration into the wound over a long period of time, resulting in the release of cytokines that induce the excessive proliferation of repair cells and scar formation (4). However, the mechanism underlying this process remains unknown. To avoid the adverse effects of scar formation, numerous studies have focused on the mechanism underlying scarless healing of burned skin (5-8). Fetal skin constitutes an attractive target for investigating scarless healing of burned skin for numerous reasons: i) Previous studies have reported that scarless healing commonly occurs in early and middle mammalian embryos; this healing ability relies not on the intrauterine environment, but on the properties of the embryo itself (9-12). ii) No apparent inflammatory immune cell infiltration into the skin has been detected during the wound healing 
process in early and middle embryos, since the inflammatory immune system is undeveloped (13). iii) Skin cells from early and middle embryos possess improved proliferative and migratory abilities compared with late embryos and infants (14). iv) Numerous types of cytokines and proteins are different in the skin of early and middle embryos, which may aid scarless healing (15-18). The present study aimed to establish an animal model carrying burned human fetal skin, which could be used to investigate the mechanisms underlying the scarless healing process of burned fetal skin. In addition, the response of burned fetal skin to treatment with human peripheral blood mononuclear cells (hPBMCs) was determined.

Lane et al (19) generated an animal model, which consisted of nude mice carrying human embryonic skin, in order to investigate the features of scarless healing outside of the womb. In addition, a previous study investigated scarless healing, which mainly involves the healing process of incision wounds (13). To the best of our knowledge, the healing mechanism differs greatly between incision wounds and burn wounds. Therefore, the present study established an animal model, which consisted of nude mice carrying burned human fetal skin, based on the animal model described by Lane et al (19). Subsequently, the development process of implanted human fetal skin and the healing process of burned human fetal skin were characterized in terms of histomorphology, and the expression levels of matrix metalloproteinase (MMP)-9 and tissue inhibitor of metalloproteinases (TIMP)-1 were detected during these processes. The effects of hPBMCs on the healing process, and on MMP-9 and TIMP-1 expression in burned human fetal skin were investigated, in order to identify the immune mechanism underlying scarless healing of burn wounds.

The present study investigated the mechanism underlying scarless healing of burn wounds outside of the womb, and may provide novel information regarding the treatment of deep-degree burn injuries.

\section{Materials and methods}

Animals, human fetal skin and ethical approval. All severe combined immunodeficient nude mice ( $n=54$; age, 6 weeks; weight $20 \pm 3.8 \mathrm{~g}$ ) used in the present study were obtained from the Animal Center of Peking University Health Science Center (Beijing, China). The mice were maintained at $20-24^{\circ} \mathrm{C}$ and 50-60\% humidity, under a 12-h light/dark cycle with ad libitum access to animal chow and water in the animal quarters at the Animal Laboratory of the Second Hospital of Shandong University (Jinan, China). All experimental procedures were conducted according to the criteria outlined in the Guide for the Care and Use of Laboratory Animals, published by the National Institutes of Health (NIH pub no. 85-23; revised 1996). All experimental protocols were approved by the Animal Care and Use Committee of the Second Hospital of Shandong University.

The present study was approved by the Ethics Committee of the Second Hospital of Shandong University. All human fetal skin specimens were obtained from abortions induced by artificial abortion vacuum aspiration at the Department of Obstetrics, The Second Hospital of Shandong University. Prior to fetal skin collection, all of the pregnant women who were undergoing the induced abortion were informed of the study and provided written informed consent permitting the use of aborted fetal tissue for scientific research and education purposes. The present study conformed to the provisions of the 1975 Declaration of Helsinki.

A total of 9 aborted fetuses (aged between 22 and 26 weeks) were obtained for use in the present study. Within $1 \mathrm{~h}$ of abortion, fetal skin from the back of the shoulders was collected under sterile conditions and washed twice with cold sterile phosphate-buffered saline (PBS). The skin was maintained in Roswell Park Memorial Institute-1640 (RPMI-1640) medium supplemented with $10 \%$ fetal bovine serum (both from Hyclone; GE Healthcare Life Sciences, Logan, UT, USA), $100 \mathrm{IU} / \mathrm{ml}$ penicillin and $100 \mathrm{mg} / \mathrm{ml}$ streptomycin (both from Beyotime Institute of Biotechnology, Haimen, China) on ice.

Establishment of a nude mouse model carrying human fetal skin. Surgery was conducted in the laminar flow operating room, which was specific-pathogen-free following disinfection with ultraviolet light for $60 \mathrm{~min}$ prior to surgery. All operative instruments were autoclaved, and the fetal skin samples were trimmed to size $\left(20 \mathrm{~mm}^{2}\right)$.

Briefly, the nude mice were anesthetized by intraperitoneal injection with $4 \%$ chloral hydrate $(312 \mathrm{mg} / \mathrm{kg})$. The skin on the dorsum of the mice was sterilized with povidone iodine solution, and was then cut to form a $20 \mathrm{~mm}^{2}$ pedicle skin flap. Following separation of subcutaneous tissue, the pedicle skin flap was opened. The trimmed fetal skin was fixed onto the dorsal muscular mantle with 5-0 MERSILK ${ }^{\circledR}$ [Johnson \& Johnson Medical (China) Ltd., Shanghai, China] and covered with Vaseline gauze. Following suturing of the skin flap, the nude mice were maintained on a HICO-Polyurethane warming blanket (Hirtz \& Co., KG, Köln, Germany) at $37^{\circ} \mathrm{C}$ until they awoke, and were then fed. Each postoperative nude mouse was administered $1 \times 10^{5} \mathrm{IU}$ penicillin by intraperitoneal injection every $8 \mathrm{~h}$ for 3 days.

A total of 2, 4, 6 and 8 weeks after surgery, the nude mice were anesthetized with $4 \%$ chloral hydrate as above and the skin flap was opened. The secreta were removed from the surface of the fetal skin, and a $5 \times 10 \mathrm{~mm}^{2}$ piece of fetal skin was collected. The Vaseline gauze was replaced with fresh gauze. Once the skin flap was sutured, the nude mice were fed again. The fetal skin sample was placed in $4 \%$ paraformaldehyde solution at $4^{\circ} \mathrm{C}$ overnight for hematoxylin and eosin (H\&E) and immunohistochemical staining.

Establishment of a nude mouse model carrying burned human fetal skin. The development of implanted human fetal skin was observed, and after 2 weeks of implantation the fetal skin that had survived and had developed stable skin appendages was chosen to establish the model of deep-degree burned human fetal skin. The temperature of the iron head of the constant temperature electric heat apparatus (The Key Laboratory of Trauma Repair Department, The First Affiliated Hospital of PLA General Hospital, Beijing, China) was adjusted to $80^{\circ} \mathrm{C}$. The nude mice were anesthetized as above and the skin flaps were opened. After cleaning the secreta on the skin surface, the heated iron head $\left(20 \times 20 \mathrm{~mm}^{2}\right)$ was gently placed on the surface of the implanted human fetal skin and kept there for $4 \mathrm{sec}$. Subsequently, the burned fetal skin was quickly covered with gauze, which was soaked with sterile PBS for cooling 
purposes, sterilized with povidone iodine solution, and covered with Vaseline gauze and sutured. Post-operation, the nude mice were administered $1 \times 10^{5} \mathrm{IU}$ penicillin by intraperitoneal injection every $8 \mathrm{~h}$ for 3 days.

Following 3, 7, 10, 14 and 21 days, the nude mice were anesthetized and the skin flaps were opened. The secreta were removed from the surface of the fetal skin, and a piece of fetal skin $\left(5 \times 10 \mathrm{~mm}^{2}\right)$ was collected. Subsequently, the Vaseline gauze was replaced with fresh gauze. Following the suturing of the skin flap, the nude mice were fed again. The fetal skin samples were placed in $4 \%$ paraformaldehyde solution at $4^{\circ} \mathrm{C}$ overnight for H\&E and immunohistochemical staining.

Separation of hPBMCs. The present study was approved by the Ethics Committee of the Second Hospital of Shandong University. All blood samples used for hPBMC separation were collected from healthy adult male volunteers (23-26 years old). All volunteers were informed about the study and provided written informed consent permitting the use of their blood sample for scientific research and education purposes. The present study conformed to the provisions of the Declaration of Helsinki. Briefly, $10 \mathrm{ml}$ blood was drawn through the median cubital vein of each volunteer and was added to $50 \mathrm{IU} / \mathrm{ml}$ heparin (Shanghai No. 1 Biochemical \& Pharmaceutical Co., Ltd., Shanghai, China) for the prevention of coagulation.

Human PBMCs were separated using density gradient centrifugation over Lymphocyte Separation Medium (Beijing Solarbio Science \& Technology Co., Ltd., Beijing, China) according to the manufacturer's protocol. Briefly, blood was diluted 1:1 with RPMI-1640 medium (v/v), and was then precisely added to the surface of the lymphocyte separation medium and centrifuged at $400 \mathrm{x}$ g for $30 \mathrm{~min}$ at room temperature $\left(25^{\circ} \mathrm{C}\right)$. Subsequently, the hPBMC layer, which was between the upper layer (plasma and platelets) and the middle layer (lymphocyte separation medium), was carefully collected and transferred into a 15-ml Falcon tube. The hPBMC layer was washed with RPMI-1640 medium and was further centrifuged at $200 \mathrm{x} \mathrm{g}$ for $10 \mathrm{~min}$ at room temperature $\left(25^{\circ} \mathrm{C}\right)$. The separated cell pellet was resuspended in RPMI-1640 medium for further experiments.

Treatment with hPBMCs. During the establishment of a nude mouse model carrying deep second-degree burned human fetal skin, hPBMCs suspended in RPMI-1640 were subcutaneously injected into the burned fetal skin immediately after the fetal skin was burned. The total number of hPBMCs injected into each nude mouse was $1 \times 10^{6}$ cells. The nude mice in the control group were injected with the same volume of RPMI-1640. Subsequently, fetal skin samples were collected as aforementioned.

Histological staining. Skin specimens were embedded in paraffin blocks following fixation with $4 \%$ paraformaldehyde solution. Subsequently, $5 \mu \mathrm{m}$ sections were obtained, deparaffinized and stained with $\mathrm{H} \& \mathrm{E}, 4$ min each dye, at room temperature. The skin sections were then examined and evaluated in random order under blinded conditions using a light microscope (CX31; Olympus Corporation, Tokyo, Japan).
Immunohistochemical staining. The MMP-9 and TIMP-1 monoclonal antibodies were purchased from Abcam (Shanghai, China). The 3,3'-diaminobenzidine tetrahydrochloride (DAB) staining kit and Polink-2 plus Polymer horseradish peroxidase detection system for mouse primary antibody were obtained from Beijing Zhongshan Golden Bridge Biotechnology Co., Ltd. (Beijing, China).

Skin sections $(5 \mu \mathrm{m})$ were deparaffinized, washed with distilled water and immersed in PBS for $5 \mathrm{~min}$. For antigen retrieval, the sections were incubated in antigen retrieval solution (Beijing Solarbio Science \&Technology Co., Ltd.) at $93^{\circ} \mathrm{C}$ for $15 \mathrm{~min}$. Subsequently, the sections were incubated in $3 \% \mathrm{H}_{2} \mathrm{O}_{2}$ at room temperature for $10 \mathrm{~min}$, and the sections were incubated with anti-MMP-9 (1:150) or anti-TIMP-1 (1:150) for $2 \mathrm{~h}$ at $37^{\circ} \mathrm{C}$. The sections were then incubated with polymer helper at room temperature for $30 \mathrm{~min}$ and were washed three times with PBS (2 min/wash). Poly peroxidase-anti-mouse/rabbit immunoglobulin $\mathrm{G}$ was added to the sections for $30 \mathrm{~min}$ at room temperature. Color of the sections was developed using DAB. Positively stained cells exhibited brownish yellow cytoplasmic granules under the light microscope. Once the color of the positive cells exhibited brownish yellow cytoplasmic granules under microscopy, and the color of cytoplasmic granules were observable yet not too dark, the sections were washed under water to terminate color development. The sections were then counterstained with hematoxylin and were mounted in glycerin jelly mounting medium.

Images of the stained skin sections were analyzed using Image-Pro Plus 6.0 software (Media Cybernetics Inc., Rockville, MD, USA). Using immunohistochemical image gray-scale analysis, integral optical density (IOD) was determined. IOD divided by sum area of the whole image was used to calculate mean optical density (MOD), which was used to evaluate the intensity of the chemical reaction of cells in every specimen.

Statistical analysis. Each experiment was conducted in triplicate. All data are presented as the mean \pm standard deviation. Dual comparisons between groups exhibiting significant values were evaluated usingone-way analysis of variancefollowed by Dunnett's test. Statistical analysis was performed using SPSS version 19.0 (IBM Corp., Armonk, NY, USA). $\mathrm{P}<0.05$ was considered to indicate a statistically significant difference.

\section{Results}

Development offetal skin subcutaneously implanted into nude mice. Following implantation under the skin of nude mice, fetal skin was observed to develop similarly to in the intrauterine environment. In the present study, skin from 23 -week-old fetuses was used as a control to determine the developmental process of fetal skin in a nude mouse model (Fig. 1).

Under the light microscope, the epidermis of the fetal skin exhibited slight keratinization, and was comprised of four layers of cells that were regularly arranged. Cells in the walls of the follicular cavity were well arranged. The hair shaft in the follicular cavity had developed but did not grow out of the epidermis. Some sweat glands could be observed, which possessed the distinct duct and secretory portions; however, 

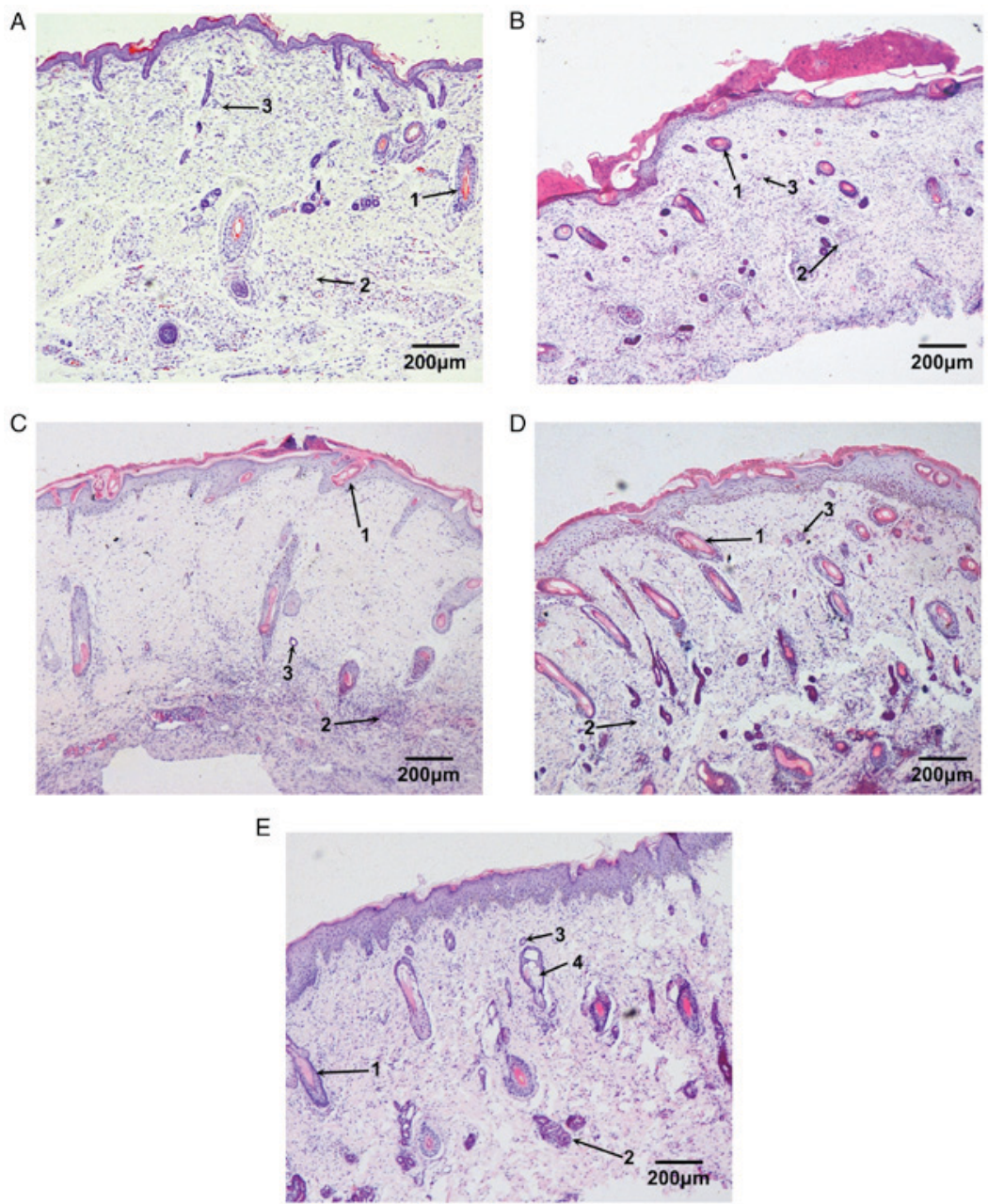

Figure 1. Development of fetal skin subcutaneously implanted into nude mice. (A) Skin from a 23-week-old fetus was stained with hematoxylin and eosin (magnification, x40). Following (B) 2 weeks, (C) 4 weeks, (D) 6 weeks and (E) 8 weeks of implantation into nude mice, the fetal skin was partially resected and observed under a microscope. Arrow 1 indicates the hair and the follicular cavity, arrow 2 indicates the sweat gland, arrow 3 indicates small blood vessels and arrow 4 indicates the sebaceous gland.

the cavity was still narrow. In addition, some undeveloped sweat glands were observed (Fig. 1A).

Following 2 weeks of implantation, the number of cell layers in the fetal epidermis was increased. New blood vessels were detected in the deep dermis and more skin appendages could be observed. The hair follicles and sweat glands possessed complete structures and larger cavities (Fig. 1B). Following 4 weeks of implantation, the number of cell layers in the fetal epidermis was further increased. The hair shaft could be seen clearly and had grown out of the epidermis. In addition, the volume of hair follicles and sweat glands was larger (Fig. 1C). Following 6 weeks of implantation, the epidermis of the fetal skin became thicker, and the papillary layer of the dermis was detected. Furthermore, the volume and number of skin appendages was markedly increased (Fig. 1D). Following 8 weeks of implantation, the fetal skin was almost completely developed, with the papillary layer apparent and obviously differentiated cuticle. The skin appendages, including sweat glands, sebaceous glands and follicles exhibited normal, complete structures and stable quantity. Some secretions could be seen in the cavity of the sebaceous glands (Fig. 1E).

Using immunohistochemical staining, the expression levels of MMP-9 (Fig. 2) and TIMP-1 (Fig. 3) were detected during the development of fetal skin outside the womb. In the skin obtained from a 23-week-old fetus, the MMP-9-positive brownish granules were widely distributed, and were mainly located in the plasma of blastemal cells, in the deep epithelial cells, and in the fibroblasts of developing skin appendages, such as follicles and sweat glands (Fig. 2A). Following 2 weeks of implantation, the skin appendages survived and grew well, their numbers were increased and their cavities became wider and larger. The expression levels of MMP-9 were slightly increased and were mostly located in the plasma of epithelial cells of skin appendages and nearby fibroblasts (Fig. 2B). Following 4 weeks of implantation, the expression levels of MMP-9 began to decrease. The MMP-9-positive cells were mostly located in fibroblasts surrounding hair follicles (Fig. 2C). Following 6 and 8 weeks, the expression levels of MMP-9 were significantly decreased and remained stable. The MMP-9-positive cells were sporadically located in the plasma of fibroblasts (Fig. 2D and E).

The expression levels of TIMP-1 were markedly lower than MMP-9. A small number of TIMP-1-positive cells were observed in the plasma of vascular epithelial cells in the dermis (Fig. 3A). Following 2 weeks of implantation, TIMP-1 expression was reduced (Fig. 3B). Following 4 weeks of 

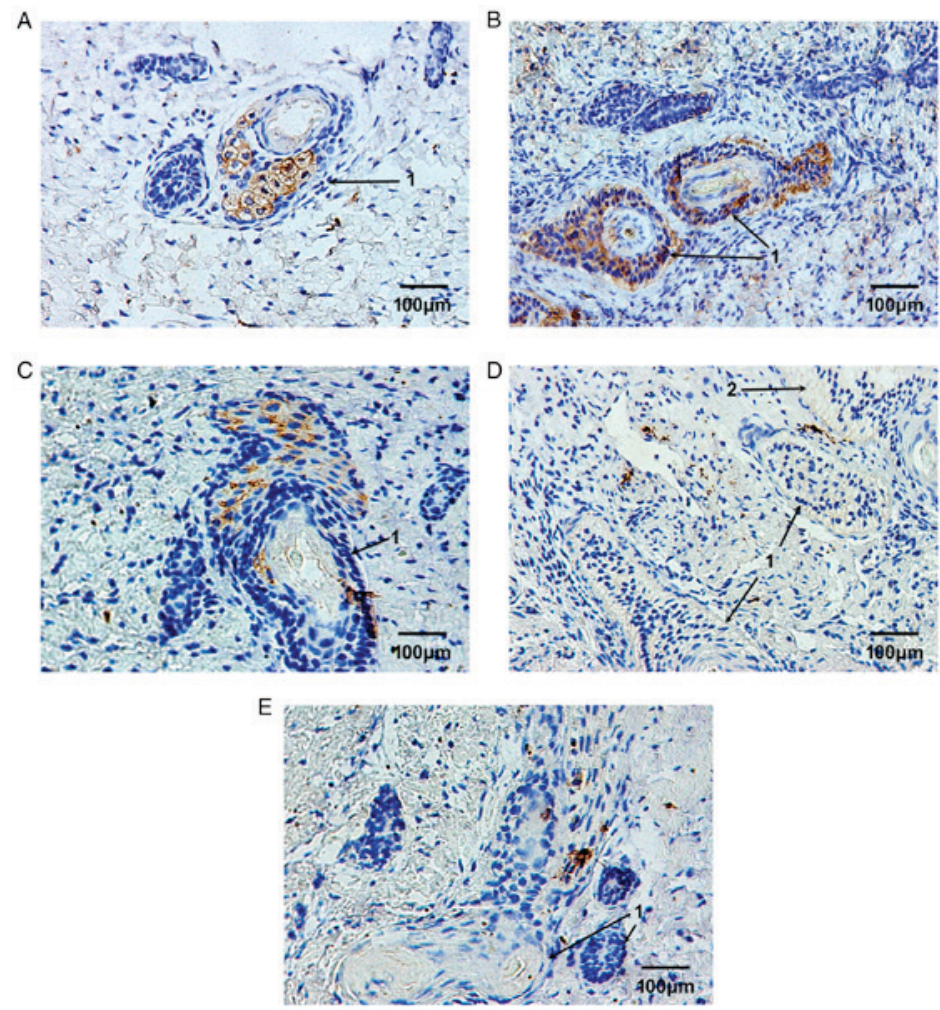

Figure 2. Expression of MMP-9 during the development of fetal skin following subcutaneous implantation into nude mice. (A) Skin from a 23-week-old fetus underwent immunohistochemical staining (magnification, x200). Following (B) 2 weeks, (C) 4 weeks, (D) 6 weeks and (E) 8 weeks of implantation into nude mice, the fetal skin was partially resected and observed under a microscope. Arrow 1 indicates the hair follicle; MMP-9-positivecells were mostly distributed around the hair follicle. Arrow 2 indicates the sebaceous gland. MMP, matrix metalloproteinase.
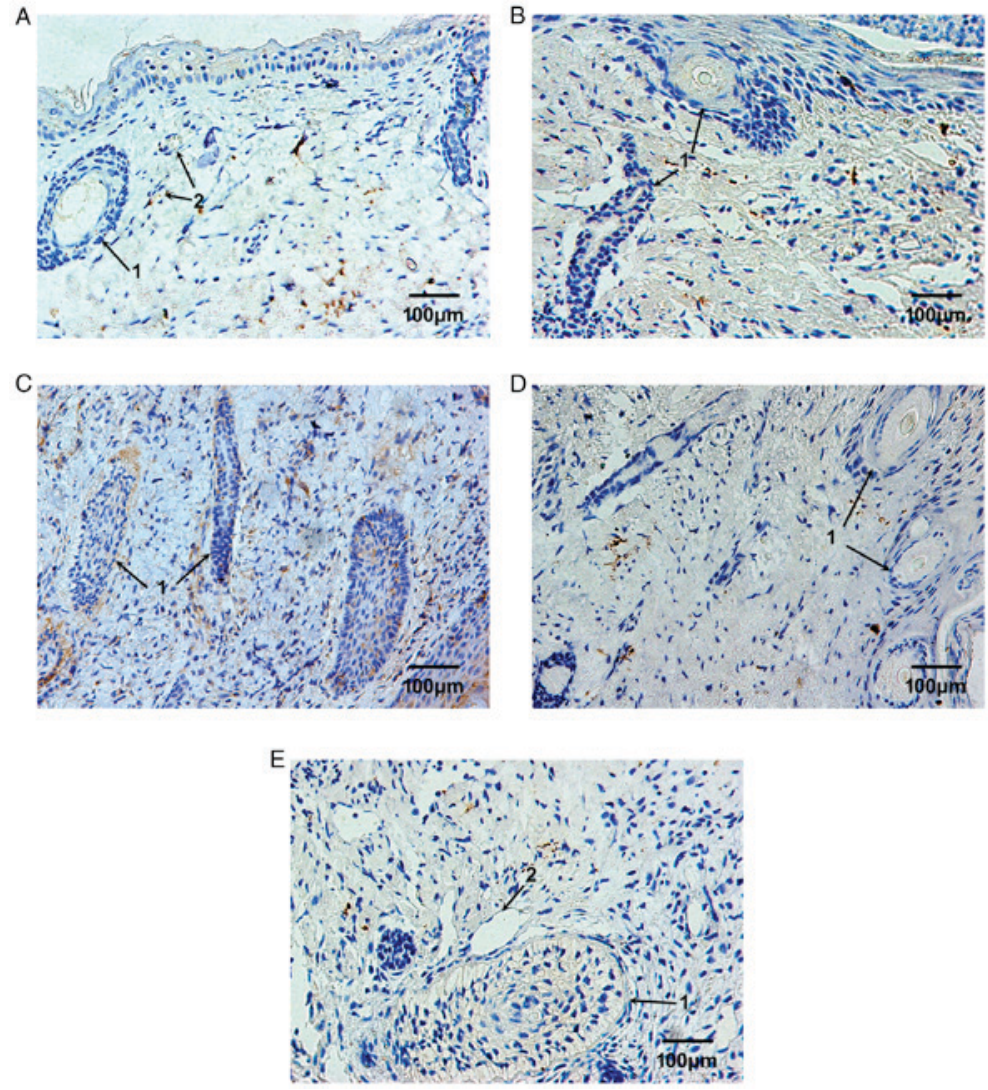

Figure 3. Expression of TIMP-2 during the development of fetal skin following subcutaneous implantation into nude mice. (A) Skin from a 23 -week-old fetus underwent immunohistochemical staining (magnification, x200). Following (B) 2 weeks, (C) 4 weeks, (D) 6 weeks and (E) 8 weeks of implantation into nude mice, the fetal skin was partially resected and observed under a microscope. Arrow 1 indicates the hair follicle and arrow 2 indicates small blood vessels. TIMP, tissue inhibitor of metalloproteinases. 


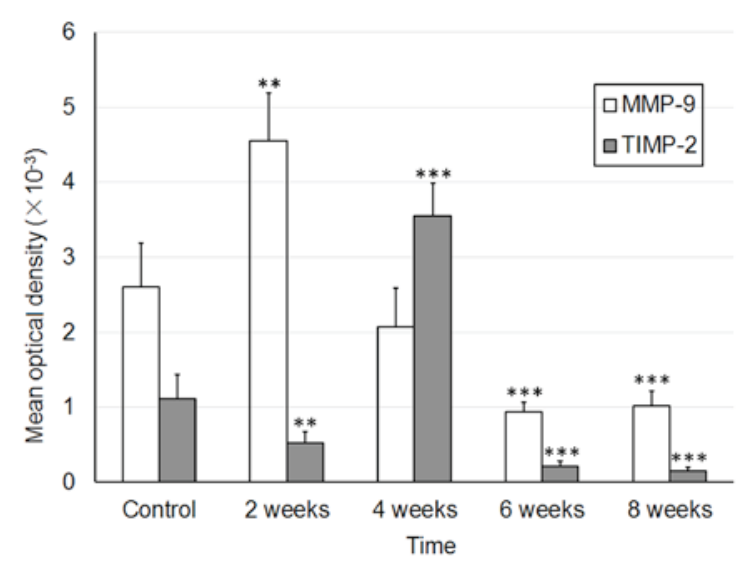

Figure 4. Mean optical density values of MMP-9 and TIMP-1 during the development of fetal skin following subcutaneous implantation into nude mice. Unimplanted skin from 23-week-old fetuses was used as the control. ${ }^{* * *} \mathrm{P}<0.01$ and ${ }^{* * *} \mathrm{P}<0.001$ vs. the control group. MMP, matrix metalloproteinase; TIMP, tissue inhibitor of metalloproteinases.

implantation, TIMP-1 expression was markedly increased; the TIMP-1-positive cells were mostly located around hair follicles with narrow cavities (Fig. 3C). Following 6 and 8 weeks, the expression of TIMP-1 was markedly reduced to a very low level; therefore, TIMP-1-positive cells were almost undetectable (Fig. 3D and E). The MOD values of MMP and TIMP-1 are presented in Fig. 4.

Repair process of burned fetal skin implanted into nude mice. The epidermis and the superficial dermis of the implanted fetal skin were removed 3 days after burn injury; the basal cell layer was absent. Under microscopy, dilated blood capillaries in the residual dermis were markedly congested. In addition, the collagenous fibers of the deep dermis were well arranged, and the structure of skin appendages, such as follicles and blood vessels, were normal. A small number of inflammatory cells infiltrated the burned tissue (Fig. 5A). Capillary hyperplasia in deep tissue and fibroblast proliferation in superficial tissue were apparent 7 days after burn injury and collagenous fibers were deposited in the normal network structure. In addition, epithelial cells of residual skin appendages migrated towards the burned surface and began to proliferate (Fig. 5B). The proliferation of the epithelial cells of residual skin appendages was markedly increased 10 days after burn injury, and the epithelial cells that had reached the burn surface began to regenerate the basal cell layer. The cavities of small blood capillaries reopened, and were larger than the normal capillary cavities. The collagenous fibers were better arranged, and sweat glands and hair follicles began to develop (Fig. 5C). The basal cell layer had completely differentiated and the integrity of repaired skin was good 14 days after burn injury; more hair follicles were developing, and appeared normal. Sweat glands continued to develop and the structure of the collagenous fiber network was regular. These observations suggested that the repair process of burned fetal skin was complete (Fig. 5D).

MMP-9 expression remained at a low level on day 3 following burn injury. The MMP-9-positive cells were located sporadically in the superficial layer of the residual dermis (Fig. 6A). With the elimination of necrotic tissues and the migration of repairing cells, MMP-9 expression was continuously increased, from day 7 to day 10 after burn injury, in the plasma of epithelial cells of residual hair follicles and sweat glands, and in nearby fibroblasts (Fig. 6B and C). Then, 14 days following burn injury, the MMP-9-positive cells were located in the plasma of epithelial cells of hair follicles and in the cells of the basal membrane, and the repair process of burned fetal skin was complete (Fig. 6D).

The expression pattern of TIMP-1 was similar to MMP-9; however, the TIMP-1-positive granules were irregularly distributed. Some of the TIMP-1-positive cells were located in the plasma of epithelial cells of skin appendages 3 days after burn injury, (Fig. 7A and B). From day 10 to 14 after burn injury, TIMP-1 expression in the plasma of epithelial cells of skin appendages, and in fibroblasts in the dermis, was markedly increased and remained so until the repair process was complete (Fig. 7C and D). The MOD values of MMP and TIMP-1 are presented in Fig. 8.

Effects of PBMCs on the repair process of deep-degree burned fetal skin. Following 3 days of treatment with PBMCs, there was no rejection reaction to the implanted PBMCs. Some inflammatory cells were detected apparently infiltrating near the burn surface and into the subcutaneous fatty layer (Fig. 9A). Following 7 days of treatment with PBMCs, some new capillaries were revealed to be developing near the burned surface and in the deep dermis. The inflammatory reaction became more obvious and more inflammatory cells had infiltrated into the fetal skin tissue. The arrangement of collagenous fibers improved, but became tighter than that observed in skin untreated with PBMCs (Fig. 9B). Following 14 days of treatment with PBMCs, the inflammatory reaction was weaker; however, more fibroblasts began to proliferate and infiltrate into the fetal skin and produce excessive collagen, which resulted in scar formation. Although collagenous fibers were deposited in the injured tissue, the collagenous fiber network was disordered. In addition, the residual skin appendages developed slowly and abnormally. The epithelial cell layer was hardly repaired, and the basal and papillary layers had not formed, and were replaced by an overgrowth of fibroblasts and collagen-like scar tissue (Fig. 9C). Compared with untreated burned skin, the repair process of burned skin treated with PBMCs was incomplete after 21 days, and hyperplastic scar tissue was detected. Epithelial cells that infiltrated near the burn surface regenerated the basal layer; however, the epithelium was incomplete and dermal papilla could not develop. The majority of skin appendages degenerated and could not develop normally. At the end point of the study, the burned fetal skin was wholly occupied by hyperplastic scar and possessed only incomplete epithelium (Fig. 9D).

MMP-9 expression was not markedly altered after 3 days of burn and PBMCs treatment (Fig. 10A). However, after 7 days of PBMCs treatment, MMP-9 expression was obviously increased in the plasma of some inflammatory cells and fibroblasts near the burn surface. In some epithelial cells of the residual skin appendages, MMP-9-positive granules were also observed (Fig. 10B). Following 14 days of PBMCs treatment, the MMP-9-positive granules were predominantly located in the plasma of proliferating epithelial cells, which infiltrated towards the burn surface. MMP-9 expression began to decrease in the plasma of fibroblasts near the burn surface. 

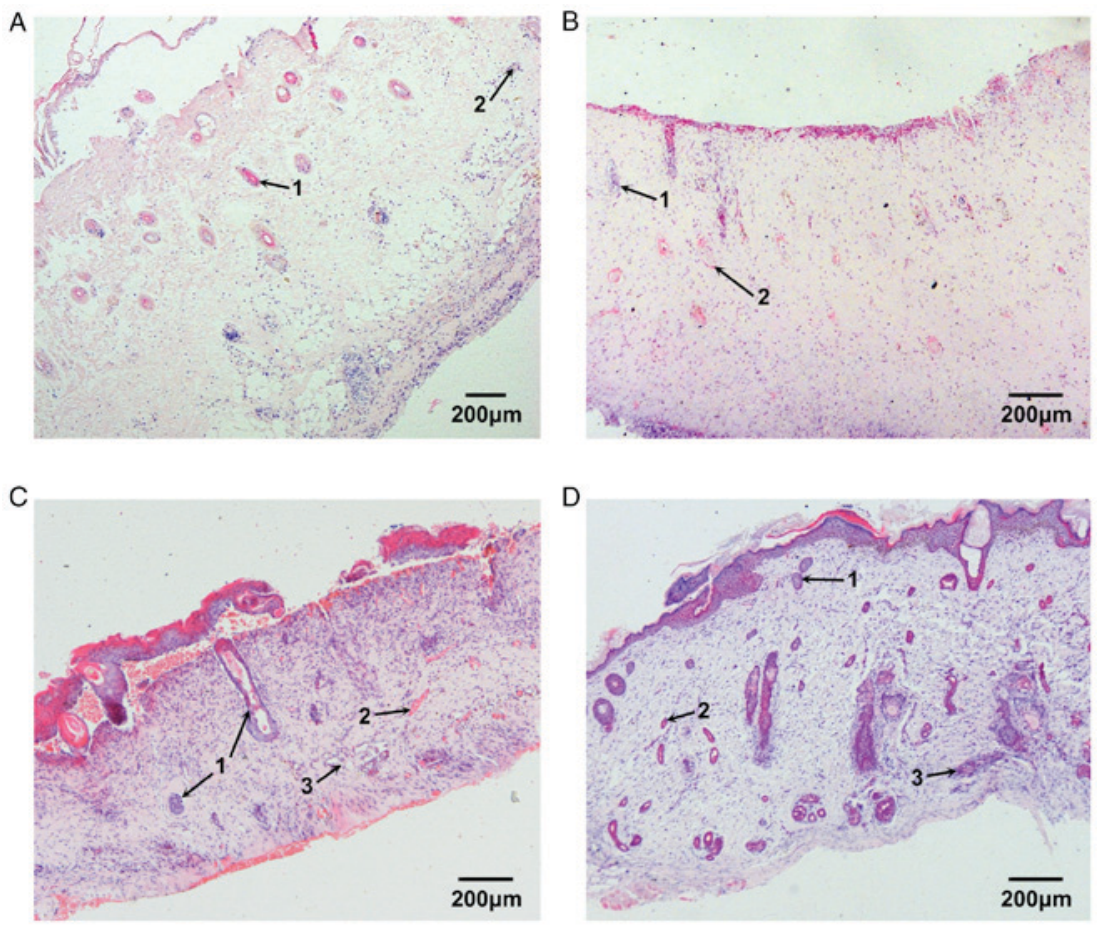

Figure 5. Repair process of deep-degree burned fetal skin following subcutaneous implantation into nude mice. (A) 3, (B) 7, (C) 10 and (D) 14 days following burn injury, the fetal skin was partially resected from the nude mice and underwent hematoxylin and eosin staining (magnification, $\mathrm{x} 40$ ). Arrow 1 indicates the hair follicle, arrow 2 indicates small blood vessels and arrow 3 indicates the sweat gland.
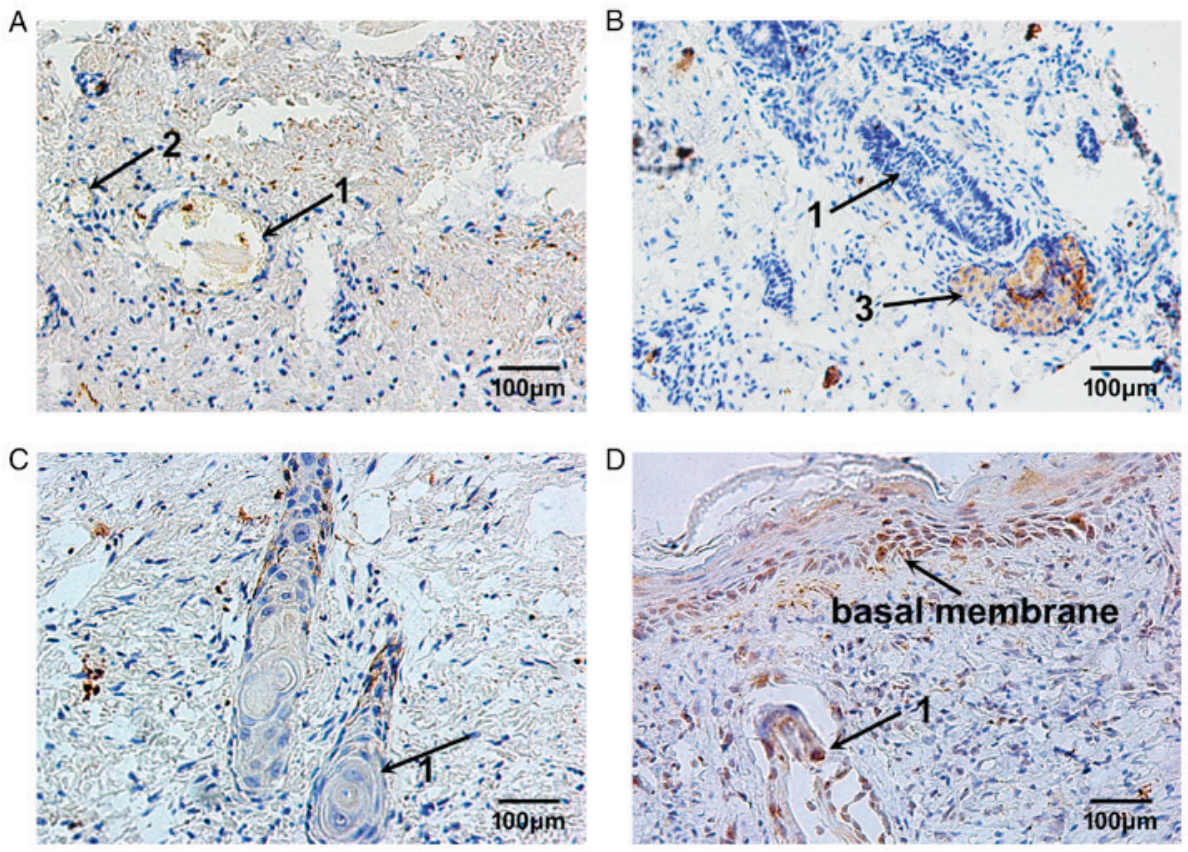

Figure 6. Expression of MMP-9 in burned fetal skin following subcutaneous implantation into nude mice during the repair process. (A) 3, (B) 7, (C) 10 and (D) 14 days following burn injury, the fetal skin was partially resected from the nude mice and underwent immunohistochemistry (magnification, $\mathrm{x} 200$ ). Arrow 1 indicates the hair follicle, arrow 2 indicates small blood vessels and arrow 3 indicates the sweat gland. MMP, matrix metalloproteinase.

In addition, MMP-9-positive granules were hardly detected in subcutaneous tissue (Fig. 10C). On day 21 following PBMCs treatment, MMP-9 expression was only detected in the local basal layer, which had completely differentiated (Fig. 10D).

In response to PBMCs treatment, the expression pattern of TIMP-1 was similar to that ofMMP-9 during the repair process of deep-degree burned fetal skin; however, it was maintained at a relatively low level. Following 3 days of PBMCs treatment, a small number of TIMP-1-positive granules were sporadically distributed (Fig. 11A). On day 7 following PBMCs treatment, TIMP-1-positive cells began to increase among fibroblasts and some cells in hair follicles (Fig. 11B). Subsequently, the expression levels of TIMP-1 were continuously increased. Finally, the distribution of TIMP-1-positive cells was located 

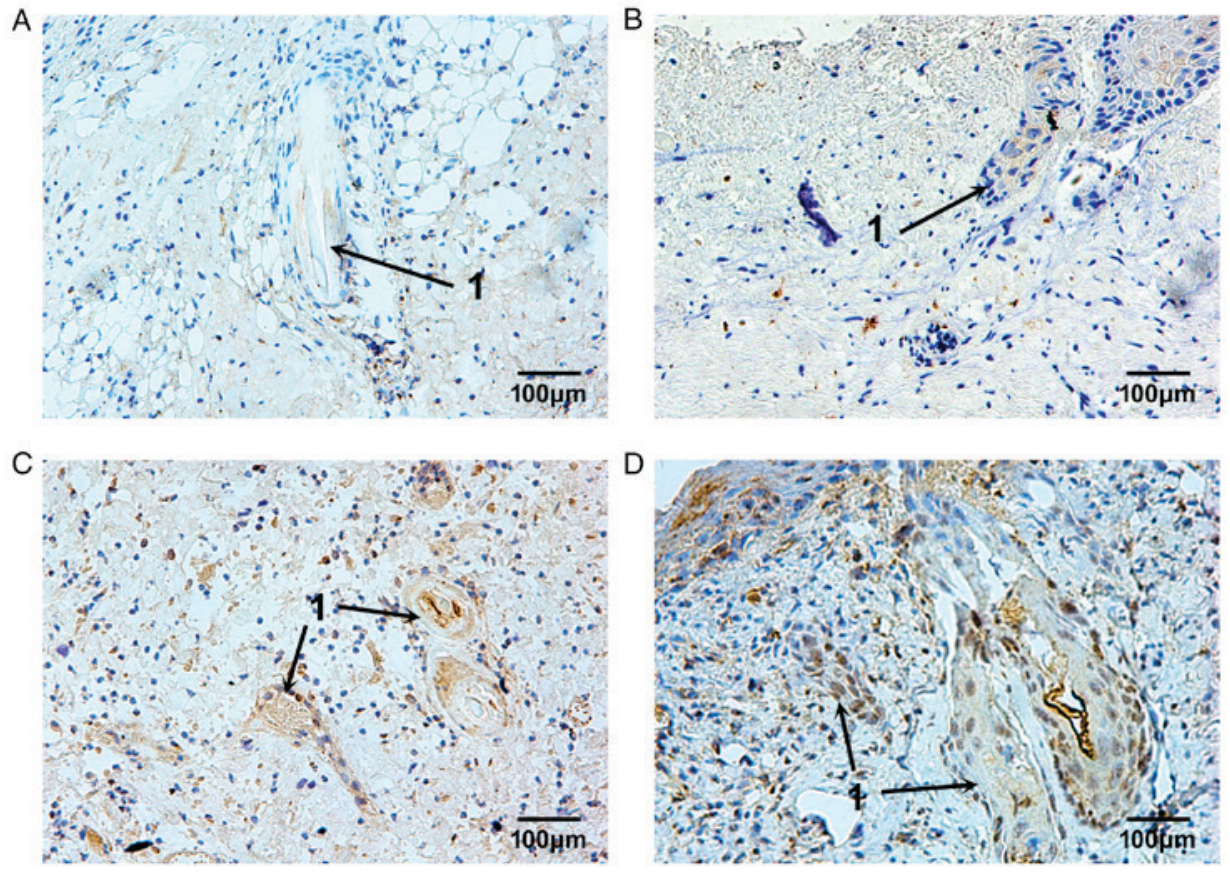

Figure 7. Expression of TIMP-1 in burned fetal skin following subcutaneous implantation into nude mice during the repair process. (A) 3, (B) 7, (C) 10 and (D) 14 days following burn injury, the fetal skin was partially resected partly from the nude mice and underwent immunohistochemistry (magnification, 200 ). Arrow 1 indicates the hair follicle. TIMP, tissue inhibitor of metalloproteinases.

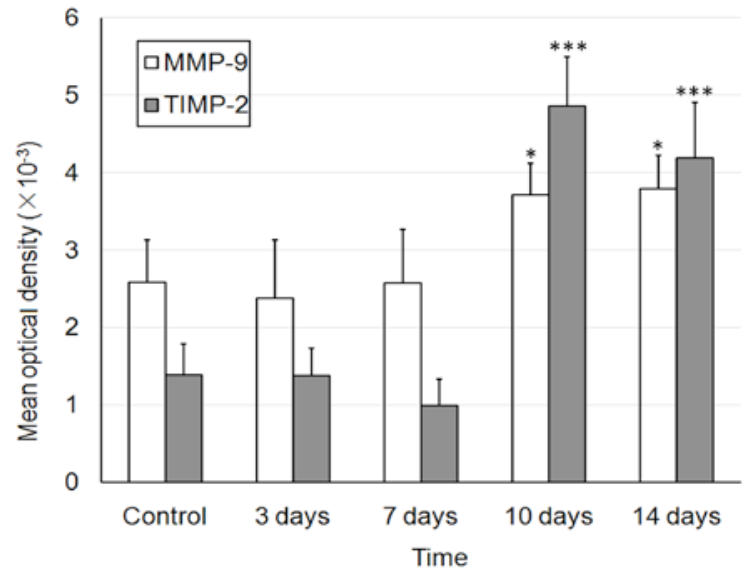

Figure 8. Mean optical density values of MMP-9 and TIMP-1 in burned fetal skin following subcutaneous implantation into nude mice during the repair process. Unimplanted skin from 23 -week-old fetuses was used as the control. ${ }^{*} \mathrm{P}<0.05$ and ${ }^{* * * *} \mathrm{P}<0.001$ vs. the control group. MMP, matrix metalloproteinase; TIMP, tissue inhibitor of metalloproteinases.

in the local basal layer, which was similar to MMP-9-positive cells (Fig. 11C and D). The MOD values of MMP and TIMP-1 are presented in Fig. 12.

\section{Discussion}

Hypertrophic scar formation and contracture following deep-degree burn-induced extensive skin defects can result in serious disability. Therefore, reducing scar formation is considered a significant issue in burn injury management $(2,20,21)$. Scarless healing, the ideal subsequent to skin injury, exists in human fetuses up to 24 weeks of pregnancy $(12,22-24)$. The amniotic fluid that surrounds the fetus is warm, sterile, and rich in nutrients, growth factors and extracellular matrix (ECM) elements, including hyaluronic acid and fibronectin, which are all important for wound healing $(12,25)$. However, in a previous study, when wounded skin from adult goats was transplanted into goat fetuses, and supplied with goat fetal blood, scar formation still occurred (26). Conversely, scarless healing has been observed in fetal skin outside the womb (19). Therefore, it may be suggested that scarless healing of fetal skin depends on the characteristics of the skin itself, and is not associated with the external environment. Identifying the mechanisms that underlies scarless healing may facilitate the clinical treatment of patients with extensive burns and could be used to generate treatments that may be applied to adult burn wounds. However, such mechanisms and treatments are not currently available.

During the healing process of incision wounds, the skin undergoes three stages: Inflammatory stage, hyperplasia stage and reconstruction stage (27). The healing process of burn wounds is complex and involves four stages: Inflammatory response, neovascularization, granulation tissue formation, and epithelium and connective tissue remodeling $(28,29)$. The healing process of deep-degree burn wounds is markedly different compared with the healing process of incision wounds. On one hand, there is apparent dermal necrosis in burn wounds, which induces chemotaxis of inflammatory cells. Inflammatory cells can aggregate together to secrete various enzymes, which can lyse and phagocytose necrotic tissue, and release numerous inflammatory factors and cytokines that can facilitate infiltration of fibroblasts and vascular epithelial cells into burned and defective tissues. On the other hand, in burn wounds, the regeneration of epithelial cells depends on proliferation, differentiation and infiltration of epithelial cells of residual skin appendages. Conversely, in incision wounds, 

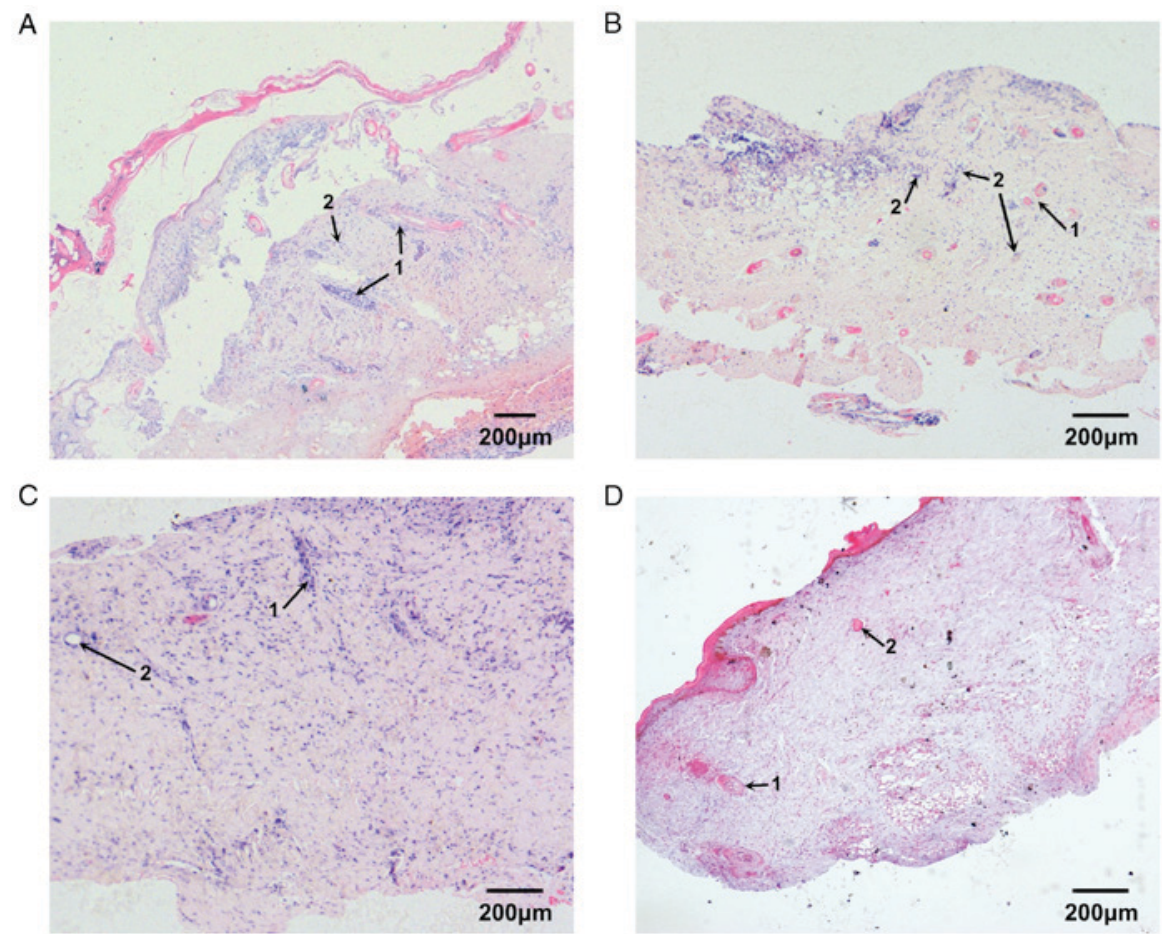

Figure 9. Repair process of deep-degree burned fetal skin implanted subcutaneously into nude mice following treatment with PBMCs. (A) 3, (B) 7, (C) 14 and (D) 21 days following burn injury and PBMCs treatment, the fetal skin was partially resected from the nude mice and underwent hematoxylin and eosin staining (magnification, $\mathrm{x} 40$ ). Arrow 1 indicates the hair follicle and arrow 2 indicates small blood vessels. PBMCs, peripheral blood mononuclear cells.
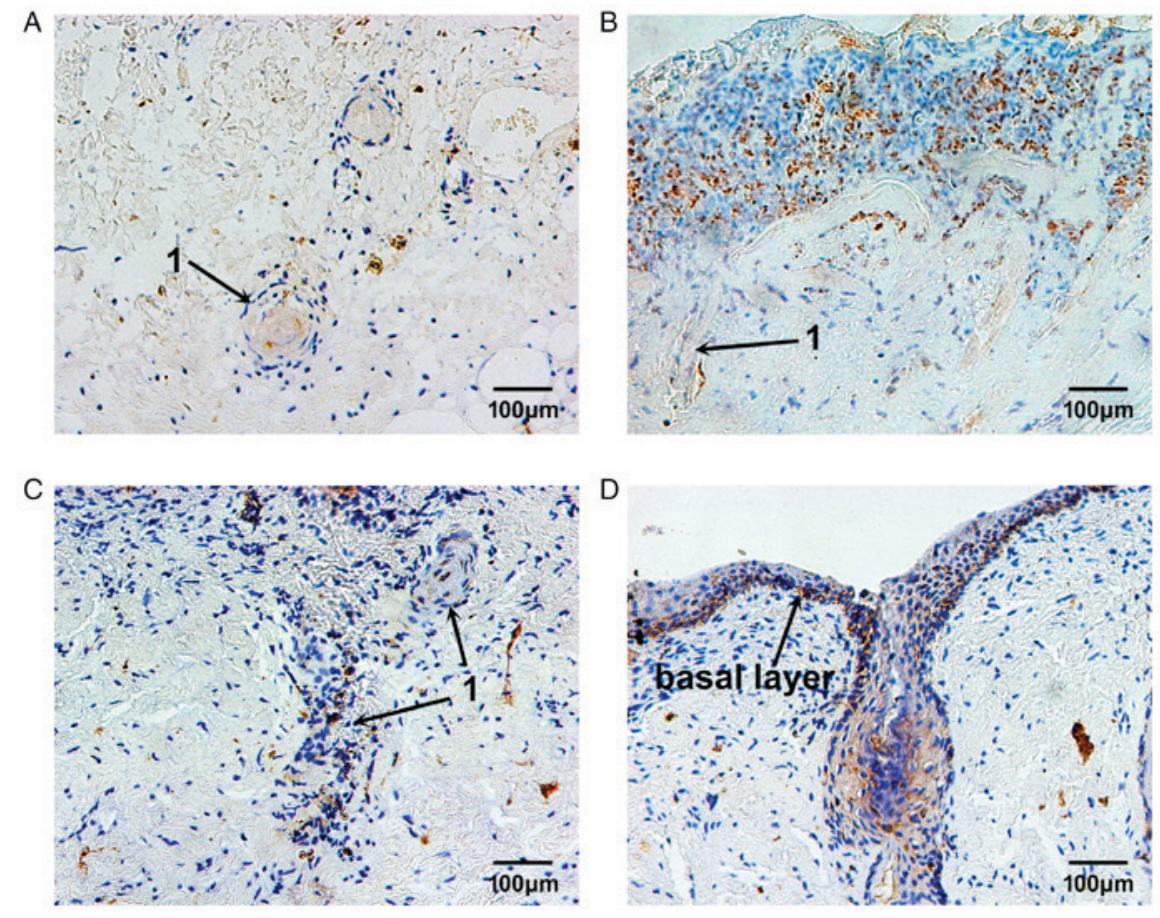

Figure 10. Expression of MMP-9 in fetal skin subcutaneously implanted into nude mice, during the repair process following burn injury and PBMCs treatment. Fetal skin was obtained and underwent immunohistochemical staining (magnification, x200). (A) 3, (B) 7, (C) 14 and (D) 21 days following burn injury and PBMCs treatment, the fetal skin was partially resected from the nude mice and underwent staining. Arrow 1 indicates the hair follicle. MMP, matrix metalloproteinase; PBMCs, peripheral blood mononuclear cells.

regenerative epithelial cells are usually sourced from the wound edge.

The present study generated a mouse model carrying burned fetal skin. In the pre-experiment, a piece of dorsal skin was cut from nude mice; the open wound was then covered and fetal skin was fixed onto the wound surface. Initially, fetal skin was superficially transplanted onto the wound, which was similar to the method used to treat burns with tissue-engineered skin. 
A

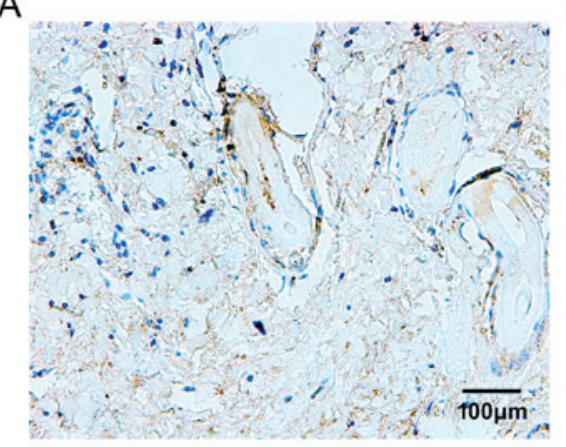

C

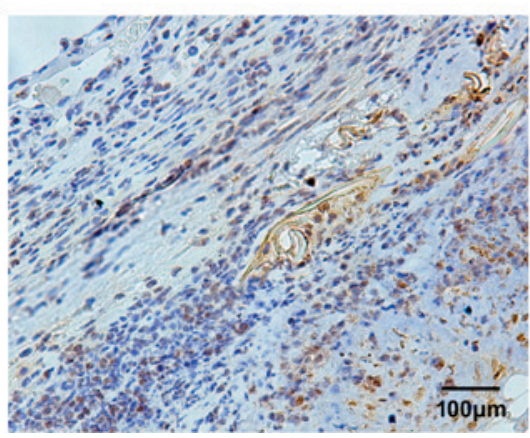

$\mathrm{B}$

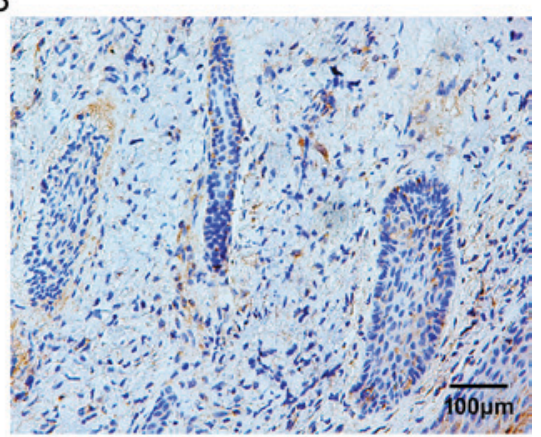

D

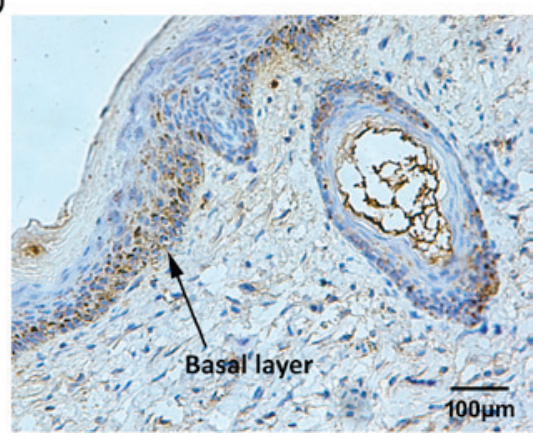

Figure 11. Expression of TIMP-1 in fetal skin subcutaneously implanted into nude mice, during the repair process following burn injury and PBMCs treatment. Fetal skin was obtained and underwent immunohistochemical staining (magnification, x200). (A) 3, (B) 7, (C) 14 and (D) 21 days following burn injury and PBMCs treatment, the fetal skin was partially resected from the nude mice and underwent staining. PBMCs, peripheral blood mononuclear cells; TIMP, tissue inhibitor of metalloproteinases.

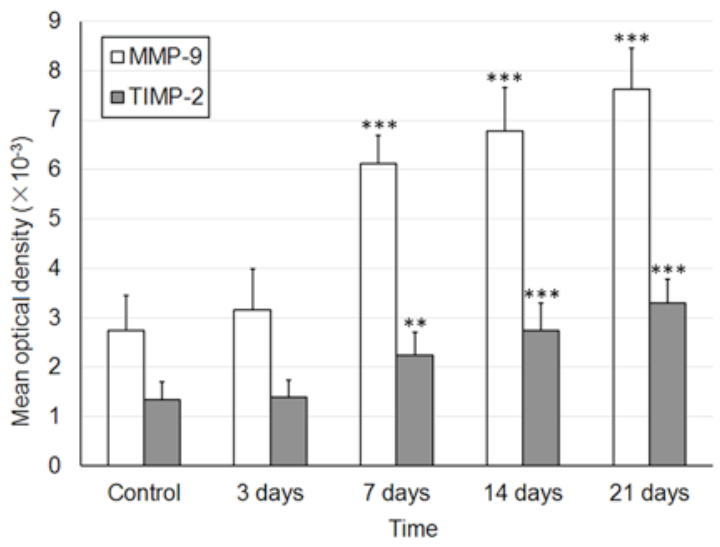

Figure 12. Mean optical density values of MMP-9 and TIMP-1 in fetal skin subcutaneously implanted into nude mice, during the repair process following burn injury and PBMCs treatment. Unimplanted skin from 23-week-old fetuses was used as the control. ${ }^{* *} \mathrm{P}<0.01$ and ${ }^{* * * *} \mathrm{P}<0.001$ vs. the control group. MMP, matrix metalloproteinase; PBMCs, peripheral blood mononuclear cells; TIMP, tissue inhibitor of metalloproteinases.

However, the transplanted fetal skin rarely survived or could not develop normally. It was hypothesized that this failure may be because the open environment was unlike the intrauterine environment; therefore, the fetal skin was subcutaneously implanted into the nude mice, which was successful.

The healing process was observed and the fetal skin was revealed to require14 days to complete the healing process following burn injury, which was less time than the same process in burned adult skin (30). In addition, the collagen fibers formed in the burned fetal skin were well arranged and similar to the fibers in unwounded fetal skin. Fetal skin has been demonstrated to possess strong proliferative and differentiative capabilities, as characterized by positive proliferating cell nuclear antigen (PCNA) expression in epithelial cells and dermal fibroblasts (31). Following burn injury, fetal skin is able to produce various cytokines, which may induce these PCNA-positive cells to proliferate, differentiate and migrate toward the wound surface, resulting in the reconstruction of defective tissues.

The present study detected no inflammatory cell infiltration during the acute inflammatory phase (2 weeks; Fig. 1B), which is similar to the healing process of incision wounds in fetal skin (13). During the healing process of wounded fetal skin, the aggregation of platelets is decreased compared with in adult skin, which may result in a decrease in the release of transforming growth factor (TGF)- $\beta 1$, TGF- $\beta 2$ and platelet-derived growth factor (32). The lack of these inflammatory factors could decrease the chemotaxis of inflammatory cells. Consequently, the lack of neutrophils may reduce the release of enzymes with the function of lysing necrotic tissues, and the injured cells may therefore die in an apoptotic manner, instead of by direct lysis. These apoptotic cells will be engulfed by fibroblasts instead of macrophages (33). Furthermore, the lack of inflammatory cells may reduce the stimulation of fibroblasts and the vascular epithelial cells, thus avoiding excessive generation of collagens and excessive hyperplasia of granulation tissue. The present study hypothesized that the mechanism underlying necrotic tissue removal in burned wound of fetal skin is similar to the hypothesis outlined above; however, further study is required for its full investigation.

The MMP family consists of collagenases, gelatinases and stromelysins $(34,35)$, all of which serve important roles 
in ECM reconstruction, epithelial regeneration and revascularization (36). TIMPs are able to suppress the activity of MMPs. During the scarless healing process, MMP expression is markedly increased and the expression of TIMP is decreased. The increasing MMP/TIMP ratio promotes the degradation of ECM and is associated with scarless healing in fetal skin (37). During the wound healing process, certain cells, including inflammatory cells and epithelial cells of skin appendages, may exhibit enhanced MMP-9 expression (38). An increased level of MMP-9 is often observed during the early inflammatory phase of wound healing (39). Repair cells, which regenerate tissues in the wound or repair damaged tissue, have an important role in the wound healing process, and proliferate, differentiate and migrate to the wound surface where they reconstruct defective tissues. Once repair cells are activated, the ECM around these cells and in their migratory path is degraded, in order to increase the migration of these repair cells. As the repair cells reach the required position, ECM is reconstructed to provide an appropriate environment for the repair cells (40). As an endogenous inhibitor of MMP-9, TIMP-1 secretion by fibroblasts can combine irreversibly with the active center of activated MMP-9, resulting in the inhibition of MMP-9 activity, which can reduce the excessive degradation of ECM molecules $(41,42)$.

In the present study, the positive expression of MMP-9 and TIMP-1 was observed in the cellular plasma of blastemal cells in the sweat glands, as well as in the epithelial cells and fibroblasts in immature skin appendages, including follicles and sweat glands. During the process of fetal skin implantation, MMP-9 expression was markedly increased after 2 weeks. With the proliferation of fibroblasts, TIMP-1 expression began to increase, resulting in the suppression of MMP-9, which was clearly observed after 4 weeks.

During the early stage of burn healing in fetal skin, the expression levels of MMP-9 and TIMP-1 remained stable, which indicated that the inflammatory response was inactivated. However, 10 days after burn injury, with the development of the skin appendages, the expression levels of MMP-9 were markedly increased, in accordance with the number of proliferating repair cells. This may have resulted in the degradation of ECM surrounding fibroblasts and epithelial cells in skin appendages, and finally the migration of proliferative repair cells to the wound surface. As the repair cells migrated to the wound surface and differentiated into a new layer of basal cells, MMP-9 expression began to decrease. Meanwhile, the expression of TIMP-1 was increased, which may further inhibit MMP-9 activity, facilitate the deposition of ECM molecules and maintain stability of the new basal cell layer (43).

Human PBMCs are a group of peripheral blood mononuclear cells, including $\mathrm{T}$ lymphocytes, which are important for regulating the inflammatory response $(44,45)$. During the process of hyperplastic scar formation in adults, numerous T lymphocytes can be detected (46); however, during the process of scarless wound healing in the oral mucosa, the number of lymphocytes is very small (47). T lymphocytes, including $\mathrm{T}$ helper (Th) and $\mathrm{T}$ suppressor cells, are involved in wound healing (48). $\mathrm{T}$ suppressor cells inhibit wound healing (49). Th1 cells are able to secrete interleukin (IL)-2 and interferon- $\gamma$, which may suppress the synthesis of collagens, and increase the expression and activity of collagenase, subsequently resulting in degradation of collagen (50). Th2 cells predominantly secrete IL-4 and IL-13, which may act on fibroblasts to promote the generation of collagen and fibronectin, thus facilitating scar formation (51). Mononuclear cells often become larger with a stronger phagocytic ability during the wound healing process, and are finally transformed into macrophages (52). Macrophages can secrete collagenase, elastase and plasminogen activator, which facilitate ECM degradation, and secrete certain cytokines, including TGF- $\beta$, epidermal growth factor, to induce an inflammatory response (53). Therefore, activated mononuclear cells can facilitate wound healing and scar formation (54).

The present study demonstrated that when PBMCs were used to treat burned fetal skin, inflammatory cells were observed near the wound surface on day 7 after burn injury. In the cellular plasma of these cells, MMP-9-positive granules were observed; this may be caused by the release of inflammatory factors from the burned fetal skin, which could induce chemotaxis of mononuclear cells and MMP-9 release. By day 14 following burn injury, the inflammatory response had become stronger and the expression levels of MMP-9 increased near the wound surface, but were reduced in the subcutaneous layer, which may be due to macrophage-induced chemotaxis of $\mathrm{T}$ lymphocytes to the wound surface. Subsequently, a number of infiltrating fibroblasts generated collagens, which exhibited a disordered arrangement, and the duration of the healing process increased. These findings indicated that $\mathrm{T}$ suppressor cells and $\mathrm{Th} 2$ cells may serve a dominant role in this process. Furthermore, fibroblasts could secrete TIMP-1 to suppress ECM degradation by inhibiting MMP-9, which resulted in the excessive deposition of collagens. Finally, scar formation occurred in the PBMCs treatment group.

In conclusion, fetal skin was subcutaneously implanted into a dorsal skin flap in nude mice. The results demonstrated that the skin exhibited similar development to that of skin grown in the womb. Subsequently, a mouse model carrying burned fetal skin was successfully established. In the mouse model, scarless healing was observed, and was completed within 2 weeks. However, following treatment with PBMCs, the burned fetal skin may generate certain inflammatory factors to induce an inflammatory response; finally, the healing process in the PBMCs-treated group was slower and associated with scar formation. MMP-9 may be associated with the proliferation of fibroblasts, whereas the inhibitory effects of TIMP-1 onMMP-9 may serve an important role in the process of scar formation. The results of the present study demonstrated that exogenous immune cells may alter the lowered immune response environment, which is required for scarless healing, resulting in scar formation. Therefore, the results suggested that the involvement of inflammatory cells is important in the healing process of deep-degree burned skin; however, the mechanism remains unclear and requires further study.

\section{Acknowledgements}

The present study was supported by the National Natural Science Foundation of China (grant nos. 30772258, 81071560 and 81372074), the Special Ally Project of Natural Science Foundation of Shandong Province (grant no. ZR2014HL060) and the Jinan Young Star Project of Science and Technology (grant no. 2013031). 


\section{References}

1. Reinke JM and Sorg H: Wound repair and regeneration. Eur Surg Res 49: 35-43, 2012.

2. Orgill DP and Ogawa R: Current methods of burn reconstruction. Plast Reconstr Surg 131: 827e-836e, 2013.

3. Fu X: Wound care in China: From repair to regeneration. Int J Low Extrem Wounds 11: 143-145, 2012.

4. Lu S, Xiang J, Qing C, Jin S, Liao Z and Shi J: Effect of necrotic tissue on progressive injury in deep partial thickness burn wounds. Chin Med J (Engl) 115: 323-325, 2002.

5. Galatz LM, Gerstenfeld L, Heber-Katz E and Rodeo SA: Tendon regeneration and scar formation: The concept of scarless healing. J Orthop Res 33: 823-831, 2015.

6. $\mathrm{Hu} \mathrm{H}$ and $\mathrm{Xu} \mathrm{AA}$ : Towards the Holy Grail: What can we do for truly scarless surgery? World J Gastrointest Endosc 7: 814-818, 2015.

7. Choi JW, Park JK, Chang JW, Kim DY, Kim MS, Shin YS and Kim CH: Small intestine submucosa and mesenchymal stem cells composite gel for scarless vocal fold regeneration. Biomaterials 35: 4911-4918, 2014.

8. Srokowski EM and Woodhouse KA: Evaluation of the bulk platelet response and fibrinogen interaction to elastin-like polypeptide coatings. J Biomed Mater Res A 102: 540-551, 2014

9. Namazi MR, Fallahzadeh MK and Schwartz RA: Strategies for prevention of scars: What can we learn from fetal skin? Int J Dermato 50: 85-93, 2011.

10. Longaker MT, Bouhana KS, Harrison MR, Danielpour D, Roberts AB and Banda MJ: Wound healing in the fetus. Possible role for inflammatory macrophages and transforming growth factor-beta isoforms. Wound Repair Rege 2: 104-112, 1994.

11. Armstrong JR and Ferguson MW: Ontogeny of the skin and the transition from scar-free to scarring phenotype during wound healing in the pouch young of a marsupial, Monodelphis domestica. Dev Biol 169: 242-260, 1995.

12. Larson BJ, Longaker MT and Lorenz HP: Scarless fetal wound healing: A basic science review. Plast Reconstr Surg 126 $1172-1180,2010$

13. Burrington JD: Wound healing in the fetal lamb. J Pediatr Surg 6: $523-528,1971$.

14. Estes JM, Adzick NS, Harrison MR, Longaker MT and Stern R: Hyaluronate metabolism undergoes an ontogenic transition during fetal development: Implications for scar-free wound healing. J Pediatr Surg 28: 1227-1231, 1993.

15. Whitby DJ and Ferguson MW: Immunohistochemical localization of growth factors in fetal wound healing. Dev Biol 147: 207-215, 1991

16. Hsu M, Peled ZM, Chin GS, Liu W and Longaker MT: Ontogeny of expression of transforming growth factor-beta 1 (TGF-beta 1), TGF-beta 3 and TGF-beta receptors I and II in fetal rat fibroblasts and skin. Plast Reconstr Surg 107: 1787-1796, 2001.

17. Colwell AS, Beanes SR, Soo C, Dang C, Ting K, Longaker MT, Atkinson JB and Lorenz HP: Increased angiogenesis and expression of vascular endothelial growth factor during scarless repair. Plast Reconstr Surg 115: 204-212, 2005.

18. Liechty KW, Kim HB, Adzick NS and Crombleholme TM: Fetal wound repair results in scar formation in interleukin-10-deficient mice in a syngeneic murine model of scarless fetal wound repair J Pediatr Surg 35: 866-873, 2000.

19. Lane AT, Scott GA and Day KH: Development of human fetal skin transplanted to the nude mouse. J Invest Dermatol 93 787-791, 1989.

20. Eldad A, Din A, Weinberg A, Neuman A, Lipton H, Ben-Bassat H, Chaouat $\mathrm{M}$ and Wexler MR: Cryopreserved cadaveric allografts for treatment of unexcised partial thickness flame burns: Clinical experience with 12 patients. Burns 23: 608-614, 1997.

21. Kagan RJ, Peck MD, Ahrenholz DH, Hickerson WL, Holmes J IV, Korentager R, Kraatz J and Pollock K: Surgical management of the burn wound and use of skin substitutes: An expert panel white paper. J Burn Care Res 34: e60-e79, 2013.

22. Julia MV, Albert A, Morales L, Miro D, Sancho MA and Garcia X: Wound healing in the fetal period: The resistance of the scar to rupture. J Pediatr Surg 28: 1458-1462, 1993.

23. Colwell AS, Krummel TM, Longaker MT and Lorenz HP: An in vivo mouse excisional wound model of scarless healing. Plast Reconstr Surg 117: 2292-2296, 2006.

24. Lorenz HP, Lin RY, Longaker MT, Whitby DJ and Adzick NS The fetal fibroblast: The effector cell of scarless fetal skin repair. Plast Reconstr Surg 96: 1251-1261, 1995.
25. Rolfe KJ and Grobbelaar AO: A review of fetal scarless healing ISRN Dermatol 2012: 698034, 2012.

26. Longaker MT, Whitby DJ, Ferguson MW, Lorenz HP Harrison MR and Adzick NS: Adult skin wounds in the fetal environment heal with scar formation. Ann Surg 219: 65-72, 1994.

27. Wang X, Jia S, Geoffrey R, Alemzadeh R, Ghosh S and Hessner MJ: Identification of a molecular signature in human type 1 diabetes mellitus using serum and functional genomics. J Immunol 180: 1929-1937, 2008.

28. Singer AJ and Clark RA: Cutaneous wound healing. N Engl J Med 341: 738-746, 1999.

29. Velnar T, Bailey T and Smrkolj V: The wound healing process: An overview of the cellular and molecular mechanisms. J Int Med Res 37: 1528-1542, 2009.

30. Tintinalli JE: Emergency Medicine: A Comprehensive Study Guide. McGraw-Hill Companies, New York, NY, pp1374-1386, 2010.

31. Kurki P, Ogata K and Tan EM: Monoclonal antibodies to proliferating cell nuclear antigen (PCNA)/cyclin as probes for proliferating cells by immunofluorescence microscopy and flow cytometry. J Immunol Methods 109: 49-59, 1988.

32. Olutoye OO, Yager DR, Cohen IK and Diegelmann RF: Lower cytokine release by fetal porcine platelets: A possible explanation for reduced inflammation after fetal wounding. J Pediatr Surg 31: 91-95, 1996.

33. Martin P, D'Souza D, Martin J, Grose R, Cooper L, Maki R and McKercher SR: Wound healing in the PU.1 null mouse-tissue repair is not dependent on inflammatory cells. Curr Biol 13: $1122-1128,2003$

34. Matrisian LM: The matrix-degrading metalloproteinases. Bioessays 14: 455-463, 1992.

35. Woessner JF Jr: Matrix metalloproteinases and their inhibitors in connective tissue remodeling. FASEB J 5: 2145-2154, 1991

36. Bullard KM, Cass DL, Banda MJ and Adzick NS: Transforming growth factor beta-1 decreases interstitial collagenase in healing human fetal skin. J Pediatr Surg 32: 1023-1027, 1997.

37. Soo C, Shaw WW, Zhang X, Longaker MT, Howard EW and Ting K: Differential expression of matrix metalloproteinases and their tissue-derived inhibitors in cutaneous wound repair. Plast Reconstr Surg 105: 638-647, 2000

38. Manuel JA and Gawronska-Kozak B: Matrix metalloproteinase 9 (MMP-9) is upregulated during scarless wound healing in athymic nude mice. Matrix Biol 25: 505-514, 2006.

39. Gillard JA, Reed MW, Buttle D, Cross SS and Brown NJ: Matrix metalloproteinase activity and immunohistochemical profile of matrix metalloproteinase- 2 and -9 and tissue inhibitor of metalloproteinase-1 during human dermal wound healing. Wound Repair Regen 12: 295-304, 2004.

40. Steffensen B, Häkkinen L and Larjava H: Proteolytic events of wound-healing-coordinated interactions among matrix metalloproteinases (MMPs), integrins and extracellular matrix molecules. Crit Rev Oral Biol Med 12: 373-398, 2001.

41. Zhao WQ, Li H, Yamashita K, Guo XK, Hoshino T, Yoshida S, Shinya T and Hayakawa T: Cell cycle-associated accumulation of tissue inhibitor of metalloproteinases-1 (TIMP-1) in the nuclei of human gingival fibroblasts. J Cell Sci 111: 1147-1153, 1998.

42. Matsumoto H, Niimi A, Takemura M, Ueda T, Minakuchi M, Tabuena R, Chin K, Mio T, Ito Y, Muro S, et al: Relationship of airway wall thickening to an imbalance between matrix metalloproteinase-9 and its inhibitor in asthma. Thorax 60: 277-281, 2005.

43. Vu TH and Werb Z: Matrix metalloproteinases: Effectors of development and normal physiology. Genes Dev 14: 2123-2133, 2000.

44. Mesko B, Poliska S and Nagy L: Gene expression profiles in peripheral blood for the diagnosis of autoimmune diseases. Trends Mol Med 17: 223-233, 2011.

45. Van der Meide PH and Schellekens $\mathrm{H}$ : Cytokines and the immune response. Biotherapy 8: 243-249, 1996.

46. Boyce DE, Ciampolini J, Ruge F, Murison MS and Harding KG Inflammatory-cell subpopulations in keloid scars. Br J Plast Surg 54: 511-516, 2001.

47. Glim JE, van Egmond M, Niessen FB, Everts V and Beelen RH: Detrimental dermal wound healing: What can we learn from the oral mucosa? Wound Repair Regen 21: 648-660, 2013.

48. Efron JE, Frankel HL, Lazarou SA, Wasserkrug HL and Barbul A: Wound healing and T-lymphocytes. J Surg Res 48: 460-463, 1990 
49. Barbul A, Breslin RJ, Woodyard JP, Wasserkrug HL and Efron G: The effect of in vivo T helper and T suppressor lymphocyte depletion on wound healing. Ann Surg 209: 479-483, 1989.

50. Wang R, Ghahary A, Shen YJ, Scott PG and Tredget EE: Human dermal fibroblasts produce nitric oxide and express both constitutive and inducible nitric oxide synthase isoforms. J Invest Dermatol 106: 419-427, 1996.

51. Fujitsu Y, Fukuda K, Kumagai N and Nishida T: IL-4-induced cell proliferation and production of extracellular matrix proteins in human conjunctival fibroblasts. Exp Eye Res 76: 107-114, 2003.
52. Serbina NV, Jia T, Hohl TM and Pamer EG: Monocyte-mediated defense against microbial pathogens. Annu Rev Immunol 26: 421-452, 2008

53. Bettinger DA, Pellicane JV, Tarry WC, Yager DR, Diegelmann RF, Lee R, Cohen IK and DeMaria EJ: The role of inflammatory cytokines in wound healing: accelerated healing in endotoxin-resistant mice. J Trauma 36: 810-814, 1994.

54. Danon D, Kowatch MA and Roth GS: Promotion of wound repair in old mice by local injection of macrophages. Proc Natl Acad Sci USA 86: 2018-2020, 1989. 